\title{
Uma proposta metodológica para estudo de segregação residencial como fenômeno relacional
}

\author{
Ítalo Matias \\ Universidade Candido Mendes - Campos dos Goytacazes - RJ - Brasil \\ ORCID: https://orcid.org/0000-0001-6683-5287 \\ Carla Nogueira Patrão de Aquino \\ Universidade Candido Mendes e Instituto Federal de Educação Ciência e \\ Tecnologia Fluminense - Campos dos Goytacazes - RJ - Brasil \\ ORCID: https://orcid.org/0000-0002-0641-5990 \\ Luiz Pereira \\ Universidade Candido Mendes e Instituto Federal de Educação Ciência e \\ Tecnologia Fluminense - Campos dos Goytacazes - RJ - Brasil \\ ORCID: https://orcid.org/0000-0001-9413-8307 \\ Fabio Freitas da Silva \\ Universidade Candido Mendes - Campos dos Goytacazes - RJ - Brasil \\ ORCID: https://orcid.org/0000-0002-3712-8265
}

\section{Resumo}

$\mathrm{O}$ artigo tem como proposta analisar a segregação residencial da área urbana do $1^{\circ}$ distrito de Campos dos Goytacazes, município localizado na Região Norte do estado do Rio de Janeiro, considerando-se as áreas dos subdistritos como unidades de análise. Para o estudo, adotou-se uma metodologia de análise da segregação associando índices não espaciais (índices de dissimilaridade e de isolamento) com a estatística espacial a partir da construção do mapa de calor, funcionalidade disponível no software de Geoprocessamento Quantum GIS. Utilizou-se, como variável, o domicílio particular permanente, segundo as classes de rendimento nominal mensal domiciliar per capita. A partir dos resultados obtidos, ficou evidenciado que $03^{\circ}$ subdistrito apresenta a área mais segregada, onde estão mais concentrados os grupos de menor renda, enquanto o grupo de maior renda concentra-se no $1^{\circ}$ e no $2^{\circ}$ subdistritos.

Palavras-chave: Dissimilaridade. Domicílio. Isolamento. Mapa de Calor. Renda. Segregação Residencial.

A methodological proposal for a residential segregation study as a relational phenomenon Abstract

The article aims to analyze the residential segregation of the urban area of the 1st district of Campos dos Goytacazes, a city located in the North region of the state of Rio de Janeiro, Brazil, considering the subdistrict areas as units of analysis. For the study, a methodology of 
segregation analysis was adopted associating non-spatial indexes (dissimilarity and isolation indexes) with the spatial statistics from the construction of the heat map, available in the Quantum GIS Geoprocessing software. As a variable, the permanent private household was used, according to the classes of monthly nominal household income per capita. From the results, it was evidenced that the 3 rd subdistrict presents the most segregated area, where the lower income groups are concentrated, while the highest income group is concentrated in the 1st and 2nd subdistricts.

Keywords: Dissimilarity. Residence. Isolation. Heat Map. Income. Residential Segregation.

\section{Una propuesta metodológica para el estudio de segregación residencial como fenómeno relacional}

\section{Resumen}

El artículo tiene como objetivo analizar la segregación residencial del área urbana del primer distrito de Campos dos Goytacazes, municipio ubicado en la región norte del estado de Río de Janeiro, Brasil, considerando las áreas del subdistrito como unidad de análisis. Para el estudio, se ha adoptado una metodología de análisis de segregación, que asocia los índices no espaciales (índices de disimilitud y aislamiento) con las estadísticas espaciales de la construcción del mapa de calor, funcionalidad disponible en el software de Geoprocesamiento Quantum GIS. La variable ha sido el domicilio privado permanente de acuerdo con las clases de ingresos nominales mensuales del hogar per cápita. A partir de los resultados obtenidos, fue evidente que el tercer subdistrito presenta el área más segregada, donde los grupos de menores ingresos están más concentrados, mientras que el grupo de mayores ingresos se concentra en el primer y segundo subdistritos.

Palabras clave: Disimilitud. Residencia. Aislamiento. Mapa de Calor. Renta. Segregación Residencial.

\section{Introdução}

A dinâmica socioeconômica é relevante para compreender os mecanismos de produção e reprodução das desigualdades sociais e sua forma de manifestação espacial. Parece acertado dizer que, no Brasil, há uma visível correlação entre o aumento populacional das cidades e o crescimento das desigualdades socioeconômicas. As formas como diferentes grupos sociais se apropriam do espaço urbano e como as cidades crescem terminam por conformar inclusão e oportunidades para uns e exclusão e marginalização para outros.

O intenso processo de urbanização a partir dos anos 1950, simultâneo ao de industrialização que o Brasil vivenciou, fez com que o país chegasse ao início do século XXI com um índice de urbanização de $84 \%$, segundo o Instituto Brasileiro de Geografia e Estatística (IBGE). Isto, porém, não representou, na mesma medida, a melhoria de vida da população. De acordo com Arretche (2015, p.6), a onda do crescimento econômico no pós-Segunda Guerra não levantou todos os barcos à mesma altura, o que reforça a natureza do sistema capitalista como concentrador de renda e gerador de desigualdades.

É pertinente relembrar que o Brasil arrasta uma herança histórica de escravidão e extrema desigualdade social e que, no processo de crescimento de suas cidades, a dicotomia sempre foi flagrante: uma cidade formal, à imagem e semelhança do "Primeiro Mundo" destinada a alguns, e outra, conduzida pelos próprios moradores nas áreas ocupadas ou adquiridas em loteamentos ilegais, 
aglomerando uma força de trabalho barata, segregada e excluída, sem vez no mercado residencial privado. Como afirma Maricato (2013, p.21) em sua narrativa, assim "como vivemos a industrialização de baixos salários, podemos dizer que vivemos a urbanização de baixos salários". Sob esta perspectiva, Piquet (2007, p. 13) observa que "o espaço é, sem dúvida, a expressão dos processos econômico-sociais que atuam sobre determinado território" e, mais que expressão, o espaço "exerce de forma retroativa importante papel na organização social resultante deste processo". Seriam, pois, as políticas que visam à distribuição de renda as definidoras de quanto um maior número de habitantes poderia aceder à riqueza do País.

Em decorrência também desses conflitos, o debate sobre a segregação residencial adquire cada vez maior importância na análise das articulações "que ligam as dimensões econômicas, culturais e políticas com as dimensões espaciais da realidade social", conforme destacam Sabatini e Sierralta (2006, p. 169), ressaltando ainda ser a moradia uma condição essencial à existência humana. Tratando-se dessa relação, Sabatini e Sierralta (Ibid.) apontam que o estudo sobre segregação residencial é ainda incipiente na América Latina e que essa possível pouca atratividade do tema pelos pesquisadores pode ser atribuída à previsibilidade de que sociedades desiguais antecipem a existência de cidades segregadas. No entanto, os autores apontam que a análise da segregação residencial, enquanto fenômeno social, é fundamental para se discutir o desenvolvimento, analisar as características e singularidades e definir as políticas e planos de ocupação do espaço urbano.

Em relação às cidades brasileiras, mesmo sendo notório que o acesso à habitação segue a trilha do poder aquisitivo dos segmentos ou das classes sociais, os estudos também são relativamente recentes e emergiram no contexto da disputa pela ocupação da terra.

Em recentes trabalhos como os de (1) Martines et al. (2020); (2) Amaral e Lima Amaral (2019); (3) Silva, Pereira e Guadagnin et al. (2018); (4) Barros, Medeiros e Morais (2017) foram analisadas a segregação espacial por meio de estudos empíricos. O primeiro buscou correlacionar a vulnerabilidade socioeconômica com padrões de uso e ocupação do solo em na cidade de Sorocaba -SP. O segundo investigou a segregação da Região Metropolitana de Goiás a luz das relações entre a dinâmica populacional, princípios de planejamento e processo de produção do espaço urbano. O terceiro analisou a segregação espacial e social em Criciúma - RS, buscou demonstrar de que maneira o processo de segregação ocorreu, quais as causas e consequências no contexto histórico e social do município. O quarto estudou a segregação espacial e a acessibilidade urbana nas capitais brasileiras Belém, Manaus, Recife e São Paulo com ênfase nos locais precários e na localização das classes sociais no espaço urbano e a sua integração à cidade.

A pretensão neste trabalho é analisar a segregação residencial a partir do estudo empírico do $1^{\circ}$ distrito do município de Campos dos Goytacazes. O foco está na área urbana, tomando como escala de análise os quatro subdistritos pertencentes ao $1^{\circ}$ distrito de mesmo nome da cidade. Para analisar esse fenômeno, buscou-se calcular os índices de dissimilaridade e de isolamento, associando esta análise à construção do mapa de calor, funcionalidade disponível no software de Geoprocessamento Quantum GIS (QGIS). 
As dimensões da segregação analisadas envolvem a concentração espacial de determinados grupos sociais e a homogeneização social de determinadas áreas. Como variável, utilizou-se o domicílio particular permanente, segundo as classes de rendimento nominal mensal domiciliar per capita, conforme Censo 2010 (IBGE).

A opção por aplicar esta metodologia no município de Campos dos Goytacazes se deu em função do forte fluxo migratório campo-cidade vivenciado pela população nas últimas décadas, consequência das alterações de natureza predominantemente econômica, muito atribuída à perda de dinamismo do setor sucroalcooleiro na transição dos anos 1980/1990. Esse processo provocou a aglomeração de antigos trabalhadores rurais em determinados locais da área urbana do município, notadamente no 30. subdistrito, à margem esquerda do rio Paraíba do Sul, o que pode ser citado como de padrão distinto à ocupação urbana primeira do município, preponderante à margem direita do mesmo rio.

O artigo vem organizado da seguinte forma: além desta introdução e das considerações finais, a seção 2 apresenta a caracterização da área de estudo; a seção 3 dedica-se ao arcabouço teórico que sustentou a discussão sobre o tema. Para medir as dimensões objetivas de segregação referenciadas por Sabatini e Sierralta, adotaram-se os métodos estatísticos: os índices de dissimilaridade e os de exposição apresentados na seção 4, além da aplicação do mapa de calor. A descrição da metodologia compõe a seção 5, acompanhada da análise da segregação residencial em Campos dos Goytacazes, com uma sequência de mapas construídos para esse estudo.

\section{Caracterização da área de estudo}

O município de Campos dos Goytacazes localiza-se na Região Norte Fluminense do estado do Rio de Janeiro. A cidade abrange, atualmente, uma área de 4.026,69 $\mathrm{km}^{2}$ e abriga uma população estimada em 487.186 (IBGE/2016). Sua densidade demográfica é de 115,16 hab/ $\mathrm{km}^{2}$. Segundo dados do IBGE (2010), o município possui 14 distritos: $\left(1^{\circ}\right)$ Campos dos Goytacazes, $\left(3^{\circ}\right)$ Santo Amaro, $\left(4^{\circ}\right)$ São Sebastião, $\left(5^{\circ}\right)$ Mussurepe, $\left(7^{\circ}\right)$ Travessão, $\left(9^{\circ}\right)$ Morangaba, $\left(1^{\circ}\right)$ Ibitioca, $\left(11^{\circ}\right)$ Dores de Macabu, $\left(12^{\circ}\right)$ Morro do Coco, $\left(13^{\circ}\right)$ Santo Eduardo, $\left(15^{\circ}\right)$ Serrinha, $\left(17^{\circ}\right)$ Tocos, $\left(18^{\circ}\right)$ Santa Maria e $\left(20^{\circ}\right)$ Vila Nova de Campos.

A Figura 1 mostra a área selecionada para o presente estudo, que corresponde ao espaço urbano dos quatro subdistritos que compõem o $1^{\circ}$ distrito da cidade de Campos dos Goytacazes. Totaliza ${ }^{1} 200,38 \mathrm{Km}^{2}$, correspondentes a $5 \% \mathrm{da}$ área total do município e onde se concentram $85 \%$ do total da população urbana do município de Campos dos Goytacazes.

Figura 1. Localização da área de estudo

\footnotetext{
${ }^{1} \mathrm{~A}$ área total (urbana+ rural) do município de Campos dos Goytacazes é de 4.026,69 $\mathrm{Km}^{2}$ e a do $1^{\circ}$ distrito é de 697,90 $\mathrm{Km}^{2}$.
} 


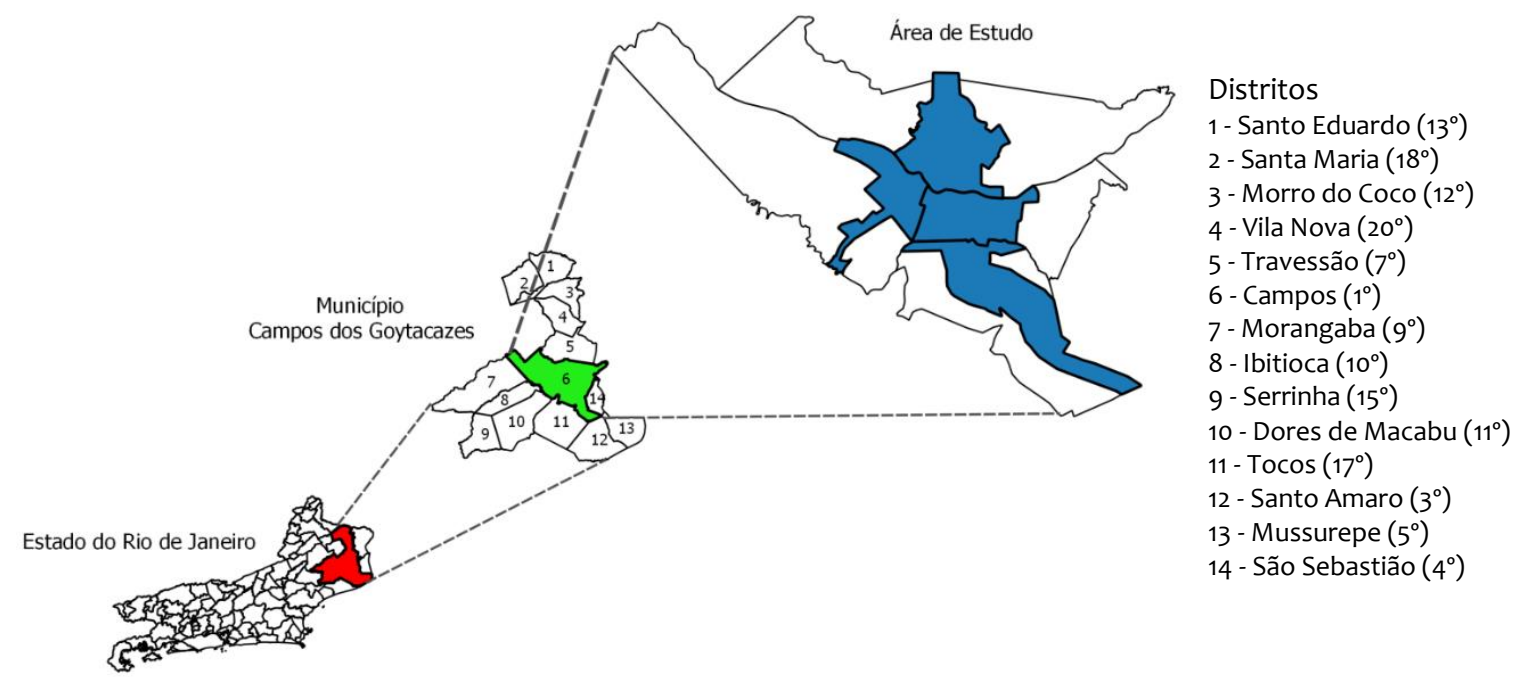

Fonte: Elaboração própria.

A Tabela 1 mostra elevada concentração na área estudada, com impactos devastadores no espaço urbano e nas áreas densamente povoadas, como é o caso do $3^{\circ}$ subdistrito, com $31 \%$ da população urbana do município.

Tabela 1. População do município de Campos dos Goytacazes e dos subdistritos 2010

\begin{tabular}{l|r|r|r|r|r}
\hline \multicolumn{1}{c|}{ Subdistritos/Distritos/Município } & \multicolumn{1}{c|}{ Total } & Urbana & \multicolumn{1}{c|}{$\%$} & Rural & \multicolumn{1}{c}{$\%$} \\
\hline $1^{\circ}$ subdistrito & 73.802 & 72.787 & 17,4 & 1.015 & 2,3 \\
$2^{\circ}$ subdistrito & 110.202 & 108.757 & 26,0 & 1.445 & 3,2 \\
$3^{\circ}$ subdistrito & 130.467 & 129.338 & 30,9 & 1.129 & 2,5 \\
$4^{\circ}$ subdistrito & 46.198 & 45.726 & 10,9 & 472 & 1,0 \\
Outros distritos & 103.062 & 62.117 & 14,8 & 40.945 & 91,0 \\
Campos dos Goytacazes (município) & 463.731 & 418.725 & 100,00 & 45.006 & 100,0 \\
\hline
\end{tabular}

Fonte: IBGE/Censo 2010.

Como se evidencia na maioria das cidades latino-americanas, Campos dos Goytacazes também cresceu dividida e desordenadamente. No caso da ocupação e uso do solo urbano, o processo se deu, inicialmente, à margem direita do rio Paraíba do Sul, com prioridade às partes mais altas, onde uma elite detentora do poder que escolhia os lugares construiria suas moradias e domínios, sendo contemplada com infraestrutura, saneamento básico e equipamentos públicos. Fora desse círculo residencial privado, em áreas precárias ocupadas ou adquiridas por valor imobiliário baixo, guetos e vielas esteiravam as franjas mal desenhadas de guetos, vielas, com moradias pequenas, geralmente geminadas. Assim foram se formando os atuais bairros e subdistritos.

Na Figura 2, percebe-se a área dos quatro subdistritos, e dá-se destaque ao rio Paraíba do Sul e à rodovia BR 101, referências importantes na formação do espaço urbano campista. 
Mumford (1998), em sua obra A Cidade na História, afirma que "[...] Se quisermos identificar a cidade, devemos seguir a trilha para trás, partindo das mais completas estruturas e funções urbanas conhecidas, para os seus componentes originários, por mais remotos que se apresentem no tempo, no espaço, na cultura [...]". Portanto, compreender o crescimento da cidade, o fenômeno da urbanização, é também revelar um processo social, político e econômico, que extrapola, e muito, o tempo e os espaços históricos.

Figura 2. Referenciais da área urbana de Campos dos Goytacazes

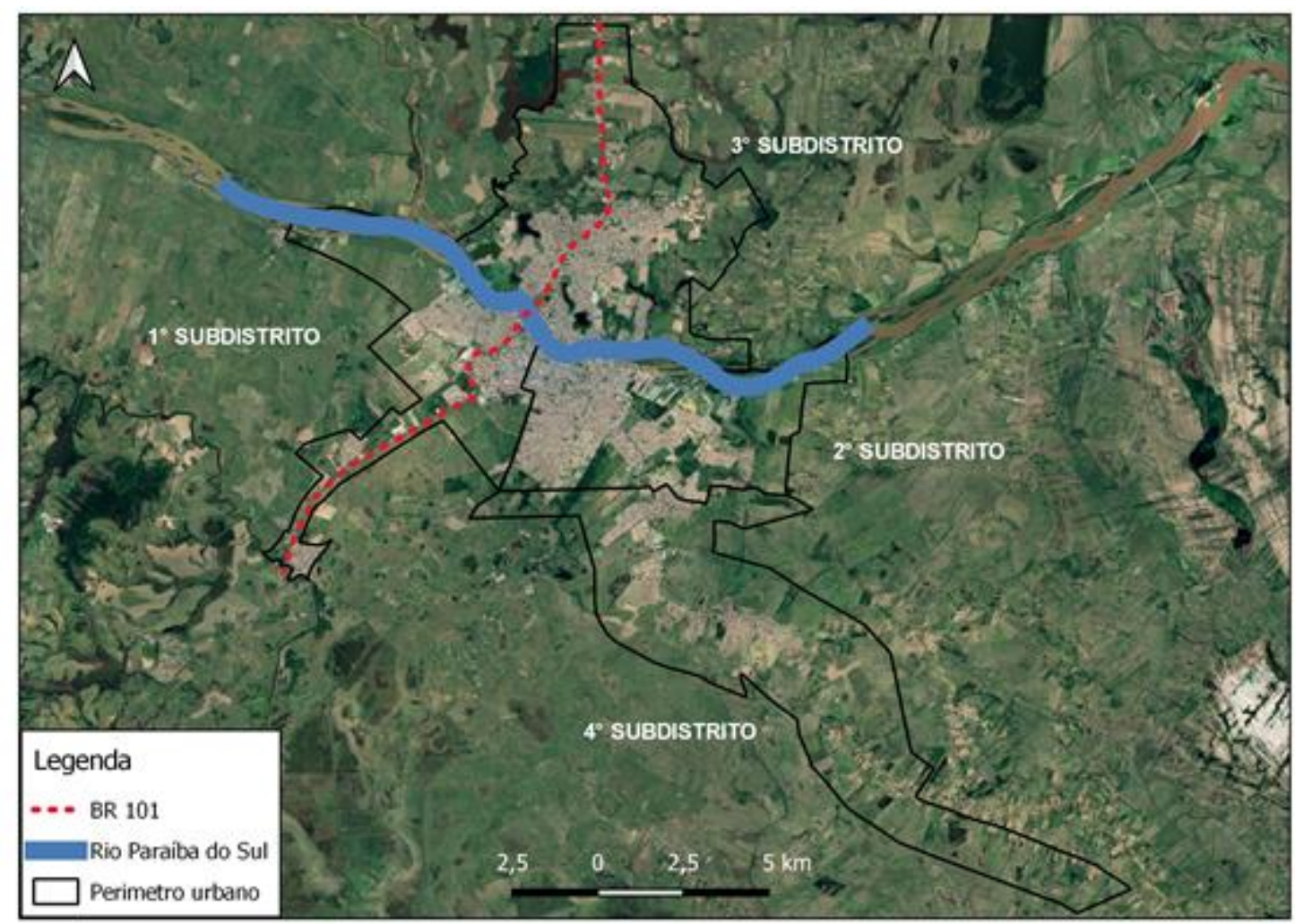

Fonte: Elaboração própria.

\section{Segregação residencial}

Segregação residencial ou segregação social do espaço urbano está associada à separação ou proximidade territorial entre pessoas ou famílias que pertencem ao mesmo grupo social (SABATINI e SIERRALTA, 2006). Apresenta-se esta como uma definição primeira sobre o fenômeno, com o propósito de se enfatizar que segregação é um fenômeno relacional, ainda que alguns autores invistam na segregação como um fenômeno per se, ou seja, isolado de outros processos sociais e explicado pela perspectiva ontológica atomista, em que as relações entre segregação residencial e outros fenômenos, como a pobreza, seriam circunstanciais.

Neste artigo, apoia-se na fundamentação de Sabatini e Sierralta. Ao reafirmarem o aspecto relacional da segregação, sua compreensão se amplia no sentido de percebê-la como "a disposição espacial aglomerada de grupos sociais 
que contribui para agravar determinados problemas para alguns grupos e para atenuá-los ou resolvê-los para outros" (Ibid., p. 185). A segregação como fenômeno social se insere, então, no debate que envolve os processos urbanos, por seu resultado, de modo geral, vir associado a impactos socialmente desfavoráveis.

Castells (1983) define a segregação residencial como uma função do nível de renda e do grau de instrução. E neste caso, a estratificação residencial ocorre com base na preferência por vizinhos com salários semelhantes.

O pensamento de Kowarick (1979) sustenta que a distribuição espacial da população reflete a condição social dos habitantes da cidade, espelhando, em nível do espaço, a segregação imperante no âmbito das relações econômicas. Para o autor, o fato de os trabalhadores residirem nas áreas distantes do centro urbano, nas favelas e cortiços, não é algo aleatório, mas algo que segue a lógica do capital na organização do espaço urbano.

A segregação enquanto fenômeno relacional pode também ser aprofundado sob o ponto de vista de outros conceitos, como por exemplo, a urbanização, os agentes sociais, o direito à cidade, a formação socioespacial, a produção do espaço urbano. Para Corrêa (2005), o espaço urbano é um reflexo da sociedade, sendo um produto social, modelado e organizado pela ação de diversos agentes. Há entre os processos sociais e a organização espacial, segundo Corrêa (Ibid., p. 122), um elemento mediador que torna viável que esses processos deem forma, movimento e conteúdo sobre o espaço. Esse mediador é os processos espaciais que, por meio de "localizações, relocalizações e permanência das atividades e população sobre o espaço urbano", são acionados por atores que modelam a organização e a reorganização do espaço, quais sejam: os proprietários dos meios de produção e de terras, as empresas imobiliárias e de construção e o Estado. Daí, a importância de uma visão mais crítica nos estudos sobre espaço urbano, uma vez que espaço urbano caracteriza-se como fragmentado, articulado, reflexo e condicionante da sociedade e campo simbólico e de lutas, em que tais características não são excludentes e podem se alterar, mas não deixam de existir.

Há diversas formas a serem aplicadas para o cálculo da segregação. Os índices de segregação podem ser classificados em três grandes grupos: indicadores entre um grupo, dois grupos e de múltiplos grupos. E em cada grande grupo, existem ainda subdivisões que identificam o que cada indicador revela: uniformidade, exposição, concentração, centralização e agrupamento, para os índices de um e dois grupos; e uniformidade e exposição, para os de múltiplos grupos:

a) Índices de segregação do tipo uniformização - analisam a dispersão em um grupo ou entre grupos. Estão inseridos neste item: o índice de segregação proposto por Duncan e Duncan (1955) para medir a dispersão em único grupo; o índice de dissimilaridade também proposto por Duncan e Duncan (1955), que mede a dispersão para dois grupos; o índice de Gini muito utilizado para o cálculo de igualdade de renda; o índice de entropia, comumente utilizado no ramo da comunicação.

b) Índices de segregação do tipo exposição - medem a probabilidade de um indivíduo encontrar membros do seu próprio grupo ou de grupos distintos. São: os índice de isolamento e de interação, que medem o quanto um está exposto ao outro membro do mesmo grupo (isolamento) ou a probabilidade de membros de 
um grupo dividir espaço com membros de outro grupo (interação); a razão de correlação que é medida entre a dispersão em cada categoria e a dispersão por todo o conjunto da população ou amostra.

c) Índices de segregação do tipo agrupamento - indicam o quão semelhante é certa área, quanto mais semelhante é a distribuição da população em um grupo em determinada área, maior será a segregação: o índice de agrupamento absoluto e o índice de agrupamento relativo.

d) Índices de segregação do tipo concentração - dizem respeito ao espaço físico que certo grupo ocupa. Quanto maior a área de ocupação do grupo, menos segregado, e se a ocupação do grupo está em um pequeno lugar, há uma grande segregação. Têm-se neste tipo: o índice delta; o índice de concentração absoluta; o índice de concentração relativa.

e) Índices de segregação do tipo centralização - medem o grau de proximidade de certo grupo com os centros das unidades de área, por exemplo, o centro da cidade. No caso de estarem perto do centro da cidade, os grupos tendem a ser concentrados. Têm-se: a proporção na área central; o índice de centralização absoluta e o índice de centralização relativa.

Como estratégia de aprofundar o entendimento sobre segregação residencial, sem pretensões conclusivas, neste artigo utilizam-se indicadores entre dois grupos.

Assim, consideram-se as três dimensões atribuídas por Sabatini e Sierralta sobre este fenômeno: a dimensão 1, que se refere à concentração (ou dispersão) espacial dos grupos; a dimensão 2, que analisa as áreas da cidade quanto à sua composição, em termos da homogeneidade ou heterogeneidade social das áreas; e a dimensão 3, que trata da percepção subjetiva que se forma sobre a segregação "objetiva" (as duas primeiras dimensões), tanto para os que pertencem a bairros ou grupos segregados como para os que estão fora deles.

A princípio pode parecer sutil a diferença entre as duas primeiras dimensões, no entanto, tal fato não se confirma. Como exemplo, é possível citar as cidades latino-americanas, onde, em uma primeira observação, de modo geral identifica-se uma concentração espacial de grupos de alta renda (dimensão 1). No entanto, como as elites sempre compartilharam estas áreas com segmentos da classe média e das classes menos favorecidas, do ponto de vista da composição social, a homogeneidade não é alta (dimensão 2). Ou seja, quando há registro de forte concentração de um mesmo grupo social em determinada área da cidade, não se pode aduzir, de imediato, que esta área seja homogênea socialmente.

As dimensões 1 e 2 de Sabatini e Sierralta se aproximam de duas apresentadas pela definição multidimensional de Massey e Denton, que concentram seus estudos sobre a segregação na sociedade norte-americana sob o aspecto racial (1988 apud SABATINI e SIERRALTA, 2006) e reconhecem que, de um lado, há a concentração (dimensão 1) com a uniformidade e dissimilaridade e, de outro, a homogeneidade social (dimensão 2) com exposição e isolamento. Face às condições distintas da realidade norte-americana em relação à latino-americana, em que as raízes do processo de segregação estão atreladas às condições socioeconômicas, há quem faça restrições a estes estudos.

Tratando-se do Brasil, o padrão de segregação residencial da década de 1950 aos anos de 1980 apresentou o espaço urbano dividido, padrão centro-periferia, 
marcado pela distância física e social entre as classes (RIBEIRO e LAGO, 1991). A elite ocupando os centros urbanos, enquanto os grupos de menor rendimento, as áreas periféricas, onde imperam a precariedade e a ilegalidade. Na década de 1990, observam-se sinais de nova configuração no padrão nas cidades brasileiras, com uma proximidade física e distanciamento social entre as classes, definido na literatura como cidade dual, cidade dividida ou espaço fragmentado. Há uma propagação da pobreza pela área urbana por meio do crescimento das áreas de maior vulnerabilidade, tanto no centro como na periferia, além da construção de novos espaços de residência, trabalho, consumo e lazer destinados às classes média e de alta renda - os condomínios residenciais fechados e shoppings centers, em lugares mais distantes do centro (RIBEIRO e LAGO, 1991; CALDEIRA, 2000; TORRES et al., 2003). Ribeiro (2003, p. 34) destaca que "deixamos o momento em que as segmentações sociais das cidades poderiam ser representadas inteiramente no modelo centro-periferia para outro em que o espaço da cidade deve ser representado como fractal".

\section{Metodologia}

A segregação residencial pode ocorrer em diferentes escalas (setores censitários, bairros, subdistritos, distritos). Em decorrência, quando se pretende mensurar a segregação residencial, metodologicamente, a primeira decisão nos estudos para essa medida é a definição da unidade de análise, uma vez que a medida de segregação de uma cidade normalmente apresenta resultados diferentes em face da adoção de distintas escalas. Com isso, reforça-se a ideia de que, na interpretação do índice de segregação, é importante ter clareza de que o índice reflete a segregação de determinada escala.

Em termos de métodos de mensuração da segregação, tomando como referência as dimensões objetivas postuladas por Sabatini e Sierralta, neste artigo serão utilizados o índice de dissimilaridade - D (concentração/dispersão espacial de determinado grupo ou segmento social) e o índice de isolamento ou de exposição xPx (homogeneidade/heterogeneidade de determinado grupo ou segmento social na unidade de análise).

O índice ' $D$ ' proposto por Duncan e Duncan indica

[...] a proporção de famílias de um determinado grupo/segmento social que deveria mudar de local da residência para que sua presença relativa em cada uma das subáreas (definida como unidade de análise) da cidade seja uniforme, isto é, para que tenha peso proporcional na população inteira da cidade (SABATINI e SIERRRALTA, 2006, p. 174).

O índice ' $D$ ' mede o grau de segregação residencial entre dois grupos populacionais: um minoritário e outro majoritário. Para isso, é necessário de imediato que se defina o segmento majoritário (os domicílios com renda nominal mensal per capita com faixa salarial entre 1/8 e 1/4 do salário mínimo) e o minoritário (os domicílios com renda nominal mensal per capita acima de 10 salários mínimos). O índice varia de 0 a 1, sendo que mais próximo de 1, maior grau de segregação. A fórmula do índice ' $D$ ' encontra-se a seguir na equação 1 : 
$D=\sum_{j=1}^{k}\left|\frac{x_{j}}{X}-\frac{y_{j}}{Y}\right| * 0,5$

em que:

$\mathrm{xj}=\mathrm{n}^{\circ}$ de pessoas do grupo minoritário em cada área $\mathrm{j} ;$

$\mathrm{X}=\mathrm{n}^{\circ}$ total do grupo minoritário;

$\mathrm{yj}=\mathrm{n}^{\circ}$ de pessoas do grupo majoritário em cada área j;

$\mathrm{Y}=\mathrm{n}^{\circ}$ total do grupo majoritário;

$\mathrm{K}=\mathrm{n}^{\circ}$ total de áreas.

À guisa de observação, os valores positivos e negativos do índice 'D' (antes da aplicação do módulo) indicam que: quando for negativo, uma parte dos domicílios minoritários deve mudar daquela área e quando for positivo, significa a necessidade de ingresso dos domicílios de outros grupos sociais. Tal movimentação de entrada e saída de residências objetiva uma distribuição igualitária dos grupos sociais em toda a cidade (PALMA, 2009).

O índice ' $D$ ' é o mais usado para um estudo empírico da segregação residencial na dimensão concentração. No entanto, apresenta alguns problemas metodológicos (SABATINI e SIERRALTA, 2006), como:

1. O índice 'D' não capta a espacialidade da segregação no interior da área estudada (problema da validade).

2. O índice 'D' não capta a segregação em uma escala maior (problema do tabuleiro de xadrez) como mostra a Figura 3. As cidades fictícias 1 e 2 apresentam o mesmo índice ' $D$ ': 3 zonas sem população cinza; 3 zonas com 1 bloco cinza; e 3 zonas com dois blocos cinzas. No entanto, na cidade 2 , a segregação é mais intensa do que na cidade 1, mas ambas permanecem com o mesmo índice ' $D$ '.

Figura 3. Problema do tabuleiro de xadrez

Cidade 1

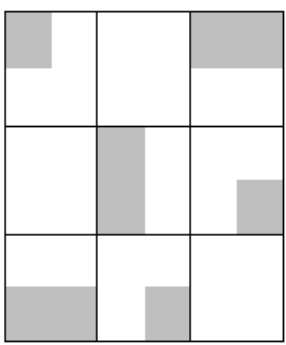

Cidade 2

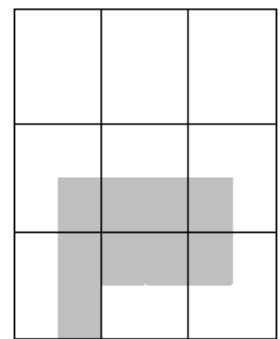

Fonte: Sabatini e Sierralta (2006).

3. O índice 'D' é alterado quando se modifica o tamanho da área; quanto menor, maior o valor do índice (problema de grade); quanto maior a área, mais se assemelha à cidade, e o índice deverá tender a zero (Figura 4). 
Figura 4. Efeito de escala sobre o valor do índice 'D'

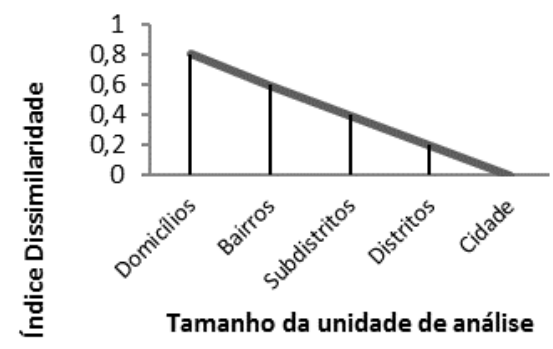

Fonte: Elaboração própria com base em Sabatini e Sierralta (2006).

$\mathrm{Na}$ dimensão isolamento/exposição, o índice de isolamento de Lieberson (1981) mede o grau de isolamento de determinado grupo em relação a ele próprio, ou seja, a possibilidade de uma pessoa morar próxima de pessoas do mesmo grupo. $O$ valor do índice xPx também varia de 0 a 1, sendo que quanto mais próximo de 0 , menor o grau de isolamento e, portanto, maior heterogeneidade social. Para o cálculo, aplica-se a seguinte equação (2):

$x P x=\sum_{j=1}^{k}\left(\frac{x_{j}}{X}\right) *\left(\frac{x_{j}}{Z_{j}}\right)$

em que:

$\mathrm{xj}=\mathrm{n}^{\circ}$ total de indivíduos do grupo $\mathrm{N}$ em cada área $\mathrm{j} ;$

$\mathrm{X}=\mathrm{n}^{\circ}$ total de indivíduos do grupo $\mathrm{N}$ em toda a área de estudo;

zj = população total na área j;

$\mathrm{K}=\mathrm{n}^{\circ}$ total de áreas.

Para Palma (2009, p. 68), o índice xPx é muito sensível à composição da população de cada área, uma vez que, nas áreas onde a presença do grupo $\mathrm{N}$ é mais significativa, os resultados tendem a ser mais expressivos.

Este artigo refere-se ao estudo empírico do $1^{\circ}$ distrito de Campos dos Goytacazes que abrange quatro subdistritos. Como unidade de referência para a medição e análise da segregação residencial, considerou-se o subdistrito. Para explorar as dimensões da segregação, adotou-se o índice de dissimilaridade proposto por Sabatini e Sierralta (2006) e o de isolamento de Lieberson (1981), e a base nos dados foi a do Censo Demográfico 2010.

Uma discussão que norteia o cálculo da segregação recai sobre a seleção das variáveis. A literatura apresenta as variáveis socioeconômicas, renda e escolaridade dos indivíduos, como das mais indicadas (CASTELLS, 1983) para medir o grau de segregação residencial. Neste estudo, optou-se por trabalhar apenas com a categoria 'renda'. As informações foram colhidas em nível municipal, selecionandose a renda dos domicílios por meio das informações indicativas do número de domicílios particulares permanentes. Os Grupos de Menor Renda (GMeR) são classificados como aqueles cuja renda nominal mensal per capita está na faixa salarial entre $1 / 8$ e 1/4 do salário mínimo (SM), enquanto o Grupo de Maior Renda (GMaR) é referente ao do número de domicílios particulares permanentes com renda acima de 10 salários mínimos per capita. 
A definição do tamanho da unidade para mensurar índices de segregação é problematizada na literatura, pois o índice de dissimilaridade tende a ser mais baixo para áreas grandes (como distritos) do que para áreas menores (como setores censitários). Assim, a decisão por subdistrito derivou dos seguintes procedimentos:

- o primeiro recorte definiu a área urbana do município, considerando que o tema a ser pesquisado refere-se à segregação residencial;

- após esta definição, foram solicitadas, ao IBGE, informações sobre a população e o número de domicílios por renda da área urbana dos 14 distritos e dos setores censitários do município de Campos dos Goytacazes no Censo 2010. Como o IBGE não dispunha de dados pelos setores censitários, disponibilizou os relativos aos distritos e subdistritos;

- com base nos dados levantados, verificou-se que $85 \%$ dos domicílios urbanos da cidade estavam localizados no $1^{\circ}$ distrito (formado pelo $1^{\circ}, 2^{\circ}, 3^{\circ}$ e $4^{\circ}$ subdistritos) enquanto os dados relativos aos restantes $15 \%$ referentes à renda do domicílio, especificamente na faixa do GMaR, se revelaram estatisticamente insignificantes, uma vez que apenas 12 domicílios (num total de 1.387) estavam localizados nos outros 13 distritos.

Ainda que seja bastante usual nas análises de segregação residencial a opção pelos setores censitários como unidade de análise, a opção pelos subdistritos (que a literatura não critica, apenas chama a atenção para a implicação sobre a variação do índice de dissimilaridade em função do tamanho da área) justifica-se pelo interesse em traçar uma fotografia da realidade do $1^{\circ}$ distrito de Campos dos Goytacazes no que se refere à ocupação do espaço urbano para fins residenciais.

Considerando que o índice ' $D$ ' não capta a espacialidade da segregação no interior da área estudada (problema de validade), a proposta central deste artigo consiste em determinar a espacialidade como atributo da concentração ou dispersão dos grupos de renda estudados. Neste sentido, a metodologia incluirá a representação espacial destes grupos (GMaR e GMeR), por meio da interpolação espacial, utilizando a variável domicílio particular permanente. Os mapas foram construídos com base na interpolação ponderada pelo inverso da distância (IDW). 0 IDW é um método clássico, sendo recomendado para regiões com alta concentração de amostras (DEUS et al. 2010, MITAS e MITASOVA, 1999). Segundo Jakob e Young (2006), tal técnica trabalha com o princípio de que as coisas mais próximas são mais semelhantes do que as mais distantes.

Para a construção destes mapas, recorreu-se, enquanto recurso metodológico, ao software gratuito de Geoprocessamento QGIS, na versão 2.18 Las Palmas. O QGIS tem versões liberadas para diversos sistemas operacionais, além de conter diversas funcionalidades na área de geoprocessamento. $\mathrm{O}$ desafio proposto foi associar índices não espaciais (como os índices de dissimilaridade e de isolamento) com a estatística espacial a partir do mapa de calor, visando obter uma análise espacial mais precisa nos estudos sobre segregação residencial.

\section{Desenvolvimento - resultados e discussões}

A origem do processo de uso e ocupação do solo urbano de Campos se deu à margem direita do rio Paraíba do Sul, no entorno da praça São Salvador (hoje Centro Histórico). Duas razões principais concorreram para isto: por ser o rio a 
principal via de circulação de pessoas e produtos na época e em função do comércio que ali se iniciou, pontos importantes para o exercício da dominação (FREITAS, 2011).

Portanto, o crescimento urbano atendeu estruturalmente ao setor industrial, com a construção de espaços de comercialização do açúcar e do álcool e à medida em que se desenvolvia o comércio. Nesta região, também se concentraram as residências das classes mais abastadas e mais heterogêneas — os proprietários das usinas, os grandes comerciantes e uma elite de profissionais liberais —, contempladas com mais infraestrutura e maior rede de serviços públicos e privados. A população de menor renda, no entanto, vai buscar a sua morada em locais mais distantes do centro, predominantemente à margem esquerda do rio, onde a realidade é diversa, marcada por domicílios mais modestos e por rede de serviços precária, num exemplo clássico da formação das cidades.

A passagem do rio Paraíba do Sul pelo município de Campos dos Goytacazes não representa apenas um elemento natural, mas um divisor social do território. É preciso considerar ainda que, na maior parte do entorno do município (à exceção da direção norte, no sentido do limite entre os estados do Rio de Janeiro e do Espírito do Santo), foram mapeadas as terras de propriedade das usinas, fato que concorreu para a existência de uma frente limitadora da expansão urbana nesta direção.

O crescimento da cidade, na maior parte do século $X X$, manteve o padrão centro-periferia. No entanto, novas configurações urbanas começam a se delinear neste século XXI, uma tendência nas cidades latino-americanas, com a construção de condomínios voltados para as classes altas, em locais mais afastados do centro, num novo formato de segregação, numa configuração socioespacial com proximidade física e distanciamento social entre as classes de maior e de menor renda. A Figura 5, na área ' $A$ ' destacada nos mapas, apresenta uma região mais heterogênea do município, constituída por moradias do GMaR e do GMeR, e também aglomerados subnormais.

$\mathrm{Na}$ comparação entre os dois mapas da Figura 5, é possível observar um contraste na distribuição dos dois grupos de renda estudados. O GMeR encontra-se distribuído por quase todo o $1^{\circ}$ distrito (lado esquerdo do mapa), o GMaR apresenta maior concentração na margem direita do rio Paraíba do Sul, próximo ao centro e com uma dispersão suave na área 'B' em destaque (lado direito do mapa). Ressaltase que a área 'A' situa-se à beira da rodovia BR-101, saída do município em direção ao estado do Rio de Janeiro; e a área 'B', na saída do município em direção ao município de São João da Barra (BR-356), o que sinaliza uma expansão nestas duas direções. 
Figura 5. Comparação entre número de domicílios do grupo de menor renda e o de maior renda no $1^{\circ}$ distrito de Campos dos Goytacazes - 2010

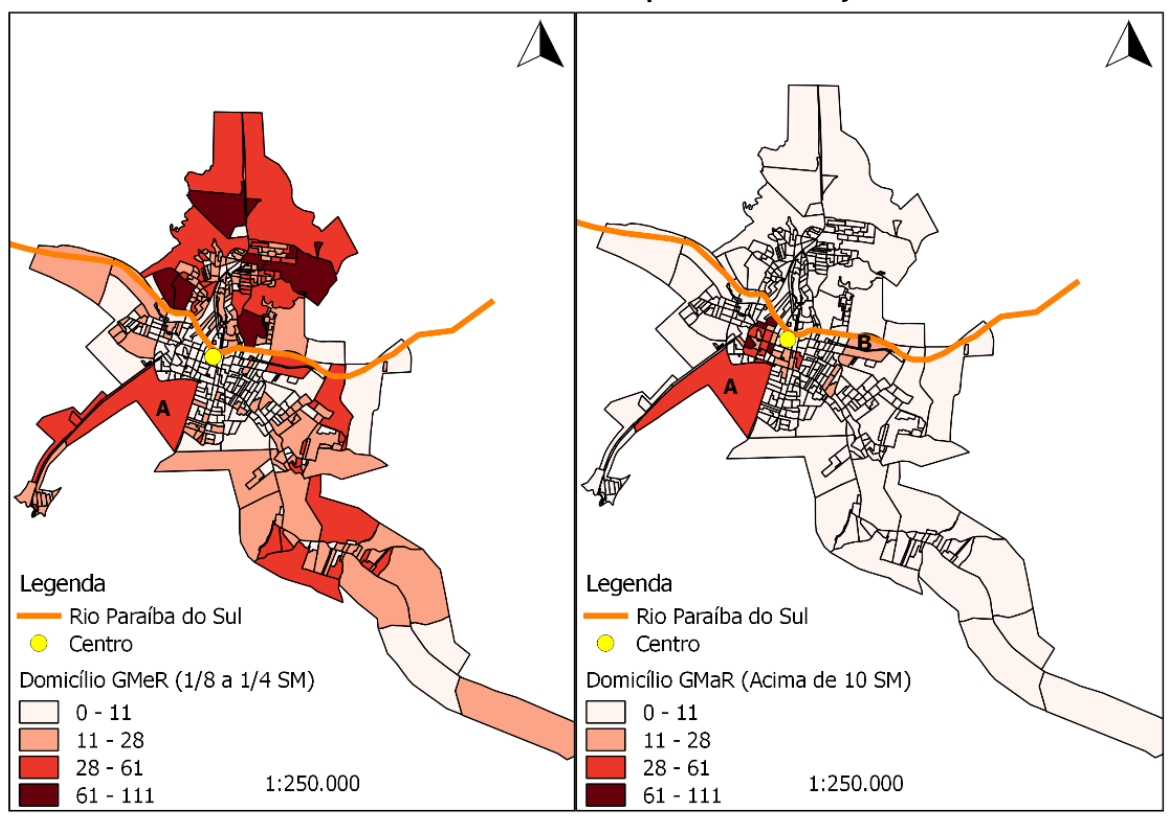

Fonte: Dados da pesquisa.

Para o cálculo do índice 'D', a fim de analisar a segregação residencial da área urbana do $1^{\circ}$ distrito de Campos, foram considerados como grupos minoritário e majoritário, respectivamente, os domicílios pertencentes ao GMaR e ao GMeR. O índice ' $D$ ' aplicado na área de estudo pode ser visualizado na Figura 6. Do ponto de vista desse índice, confirma-se o já exposto sobre a ocupação urbana à margem esquerda do rio, ou seja, o $3^{\circ}$ subdistrito, no seu conjunto, é o que apresenta de forma mais visível os maiores sinais de pobreza, com o maior índice de dissimilaridade $(0,19060)$, demonstrando a maior segregação residencial em relação ao perímetro urbano do $1^{\circ}$. distrito. 
Figura 6. Dissimilaridade dos domicílios particulares permanentes do grupo de menor e o de maior renda nos subdistritos de Campos dos Goytacazes - 2010

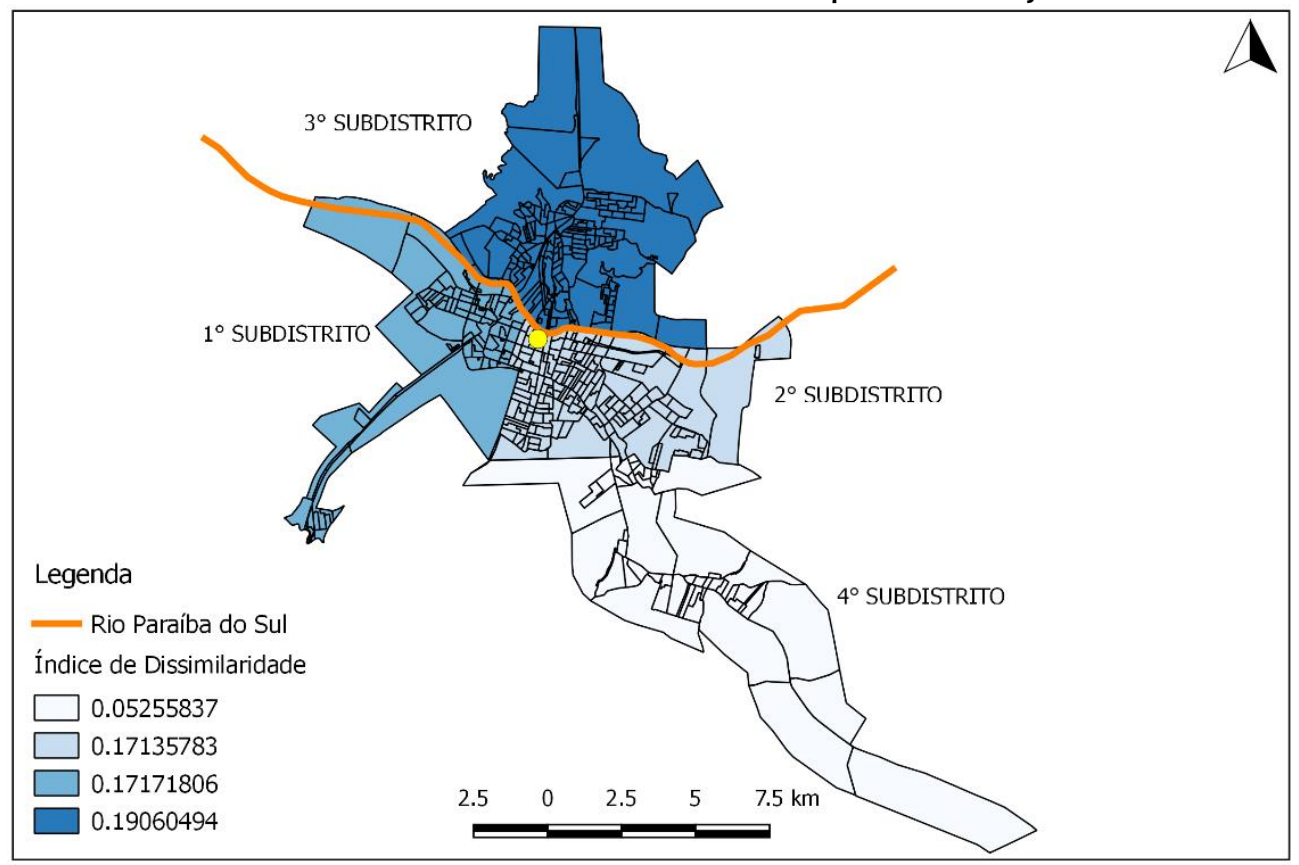

Fonte: Dados da pesquisa.

Resultado semelhante ao da dissimilaridade, o maior índice de isolamento dos domicílios foi o do $3^{\circ}$ subdistrito (0,05021), conforme Tabela 2, indicando alta homogeneidade do conjunto de domicílios que pertencem ao GMeR, ou seja, com maior probabilidade de moradores destes domicílios morarem próximo de pessoas do seu grupo social. Por outro lado, neste subdistrito, o isolamento do GMaR $(0,00005)$ é muito baixo, confirmando a homogeneidade do GMeR.

Em função de o índice 'D' não captar a espacialidade da segregação no interior da área estudada, introduziu-se na análise da segregação residencial o mapa de calor, com o objetivo de identificar se há concentração ou dispersão do GMaR e do GMeR. Observa-se, especificamente com base nesta ferramenta que, no limite do perímetro do $3^{\circ}$ subdistrito (Figura 7-D), há uma distribuição relativamente uniforme com baixa concentração do GMaR (tonalidade azul). Por outro lado, quando a análise recai sobre o GMeR (Figura 8-D), constata-se, por quase toda área do subdistrito, uma alta concentração (tonalidade vermelha) deste segmento, apenas entrecortada por pequena faixa de média para baixa concentração (tonalidades intermediárias) do mesmo grupo (área destacada no mapa).

Tabela 2. Índices de Dissimilaridades e de Isolamento de domicílios particulares permanentes do grupo de menor e o de maior renda nos subdistritos de Campos

\begin{tabular}{c|c|c|c}
\multicolumn{4}{c}{ dos Goytacazes - 2010 } \\
\hline \multirow{2}{*}{ Subdistritos } & \multirow{2}{*}{ Dissimilaridade } & Isolamento \\
\cline { 3 - 4 } & & Entre 1/8 e 1/4 SM & Acima de 10 SM \\
\hline $1^{\circ}$ & 0,17172 & 0,00651 & 0,01281 \\
$2^{\circ}$ & 0,17136 & 0,00697 & 0,00968 \\
$3^{\circ}$ & 0,19060 & 0,05021 & 0,00005 \\
$4^{\circ}$ & 0,05256 & 0,01028 & 0,00001 \\
\hline
\end{tabular}

Fonte: Dados da pesquisa. 
O exercício das análises simultâneas dos mapas de calor no perímetro que limita $03^{\circ}$ subdistrito (Figuras 7-D e 8-D) confirma que, naquela região, há uma forte concentração e homogeneidade de domicílios do GMeR, formando uma região constituída, em sua absoluta maioria, pela população mais pobre do $1^{\circ}$ distrito.

Com 0 índice ' $D$ ' calculado em 0,19060 para $0 \quad 3^{\circ}$ subdistrito, comparativamente maior que o dos demais subdistritos estudados, reitera-se ser este índice certificador da condição de área detentora de maior segregação residencial entre as que constituem o perímetro urbano de Campos dos Goytacazes. Sierralta e Sabatini destacam ser fundamental considerar a dimensão subjetiva na análise objetiva da segregação (expressa pelos índices de dissimilaridade e isolamento) e, ao chamar a atenção para as fragilidades características do índice de dissimilaridade, recomendam a indispensável importância de sua leitura em conjunto com o índice de isolamento, estes - como anotados na Tabela 2 -, 0,05021 e 0,00005, respectivamente, para o GMaR e o GMeR do $3^{\circ}$ subdistrito.

Considerando que o índice de dissimilaridade está relacionado à concentração/dispersão e o de isolamento, a uma medida de exposição entre pares de um mesmo grupo, e que o valor do índice de isolamento do GMeR (Tabela 2) é mais de mil vezes superior ao do GMaR, esses aspectos permitem inferir, ao cotejar os índices de dissimilaridade, o de isolamento e os mapas de calor (Figuras 7 e 8) que a significativa segregação residencial no $3^{\circ}$ subdistrito se manifesta como resultado da extensa e elevadíssima densidade das residências do GMeR a ponto de concentrar e homogeneizar espacialmente este grupo naquele subdistrito. A materialização da segregação residencial pode também ser representada pela apartação social de todo o $3^{\circ}$ subdistrito em comparação com os demais. Reafirmase, portanto, que a faixa por onde correm as águas do Rio Paraíba do Sul é elemento simbólico e funcional dessa insulação.

A análise da segregação residencial nos $1^{\circ}$ e $2^{\circ}$ subdistritos mostra forte semelhança quando se comparam vis à vis os índices de dissimilaridade, 0,17172 e 0,1713, e os de isolamento, de 0,00651 e 0,00697, para o GMeR e o GMaR, respectivamente (Tabela 2 ). Da mesma forma, confirma-se esta análise pelos mapas de calor (Figuras 7-B e 7-C e 8-B e 8-C). Os dois subdistritos situados à margem direita do Rio Paraíba do Sul são confrontantes no alinhamento norte-sul, localizado a oeste como $1^{\circ}$ subdistrito e o $2^{\circ}$ subdistrito, a leste (aproximadamente, a $2 \mathrm{~km}$ do centro do município). A análise dos mapas de calor apresenta alto adensamento residencial do GMaR na confluência dos dois subdistritos que, de forma contínua e quase uniforme, avança a sudoeste do $1^{\circ}$ subdistrito, formando uma mancha (ver Figura 7-A). É possível observar, pela Figura $8-C$, que $02^{\circ}$ subdistrito apresenta alguns pontos esparsos (mais ao extremo leste) com elevada concentração do GMeR, à margem do "rio Paraíba do Sul, onde se localizam alguns aglomerados subnormais.

O mapa de calor mostra que sobressai, no $2^{\circ}$ subdistrito, moderado equilíbrio na distribuição espacial em toda a sua região de média densidade do GMaR e do GMeR, com razoável adensamento entre forte e média densidade do GMeR na sua metade final a leste.

A segregação residencial do $1^{\circ}$ subdistrito em muito se assemelha à do $2^{\circ}$ subdistrito, conforme revela a proximidade entre os índices de dissimilaridade e 
isolamento. Se algum registro de maior dessemelhança cabe, pode se traduzir ao adensamento de maior proporção do GMeR a sudoeste do município de Campos dos Goytacazes (na área ' $C$ ' em destaque na Figura 8-A) e seu entorno, região cortada pela rodovia BR 101. À exceção desse registro, dada a semelhança, pode-se identificar a segregação residencial do $1^{\circ}$ subdistrito 'como espelho' do $2^{\circ}$ subdistrito e vice-versa. Enfim, a segregação residencial dos dois subdistritos, registrada pelos respectivos índices de dissimilaridade, revela-se por uma maior exposição entre o GMaR e o GMeR, observados os valores baixos (Tabela 2) dos índices de isolamento e a representação dos mapas de calor (Figuras 7 e 8 ).

Tratando-se da análise da segregação residencial do $4^{\circ}$ subdistrito, constituído por apenas três bairros, segundo o IBGE, com localização contígua e fronteiriça ao sul do $2^{\circ}$ subdistrito e com a menor população urbana entre os quatro subdistritos estudados, é possível distinguir esta área como a de menor segregação residencial se observado o seu índice de dissimilaridade $(0,05256)$. No entanto, tratando-se de índices de isolamento de 0,01028 e 0,0001, respectivamente, do GMeR e do GMaR (Tabela 2), tomando como parâmetro os subdistritos, o GMeR tem exposição mais próxima aos $1^{\circ}$ e $2^{\circ}$ subdistritos e o $G M a R$, mais próximo do $3^{\circ}$ subdistrito. As análises dos mapas de calor ${ }^{2}$ (Figuras 7-E e 8-E) mostram que esse subdistrito apresenta, à exceção de algumas aglomerações, maior densidade do GMeR em pontos dispersos. O que sobressai é a variação da densidade: os GMeR, de forte para média intensidade; e os grupos de alta renda, com baixa intensidade. Infere-se, portanto, que a segregação residencial do perímetro urbano do $4^{\circ}$ subdistrito caracteriza-se por não ser acentuada e ser razoável a exposição entre os grupos.

\footnotetext{
${ }^{2}$ Para análise do mapa de calor, neste artigo, associa-se à tonalidade vermelha, uma alta concentração; à verde, média concentração; à azul, baixa concentração; e às tonalidades, respectivamente, intermediárias, interposições proporcionais na concentração segundo o grupo de renda considerado.
} 
Figura 7. Mapa de calor da variável domicílio particular permanente do grupo de maior renda dos subdistritos de Campos dos Goytacazes - 2010
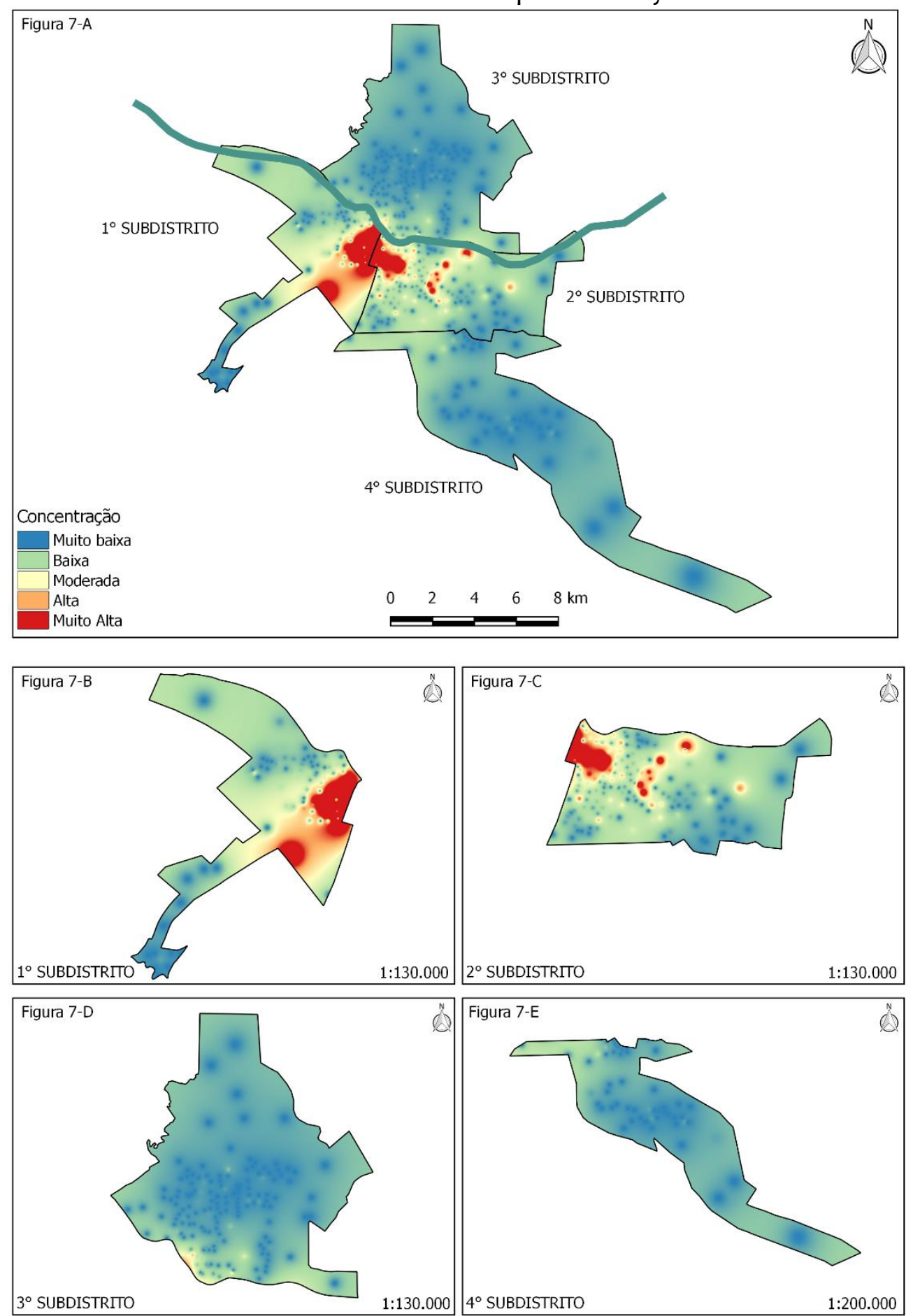

Fonte: Dados da pesquisa. 
Figura 8. Mapa de calor da variável domicílio particular permanente do grupo de menor renda dos subdistritos de Campos dos Goytacazes - 2010
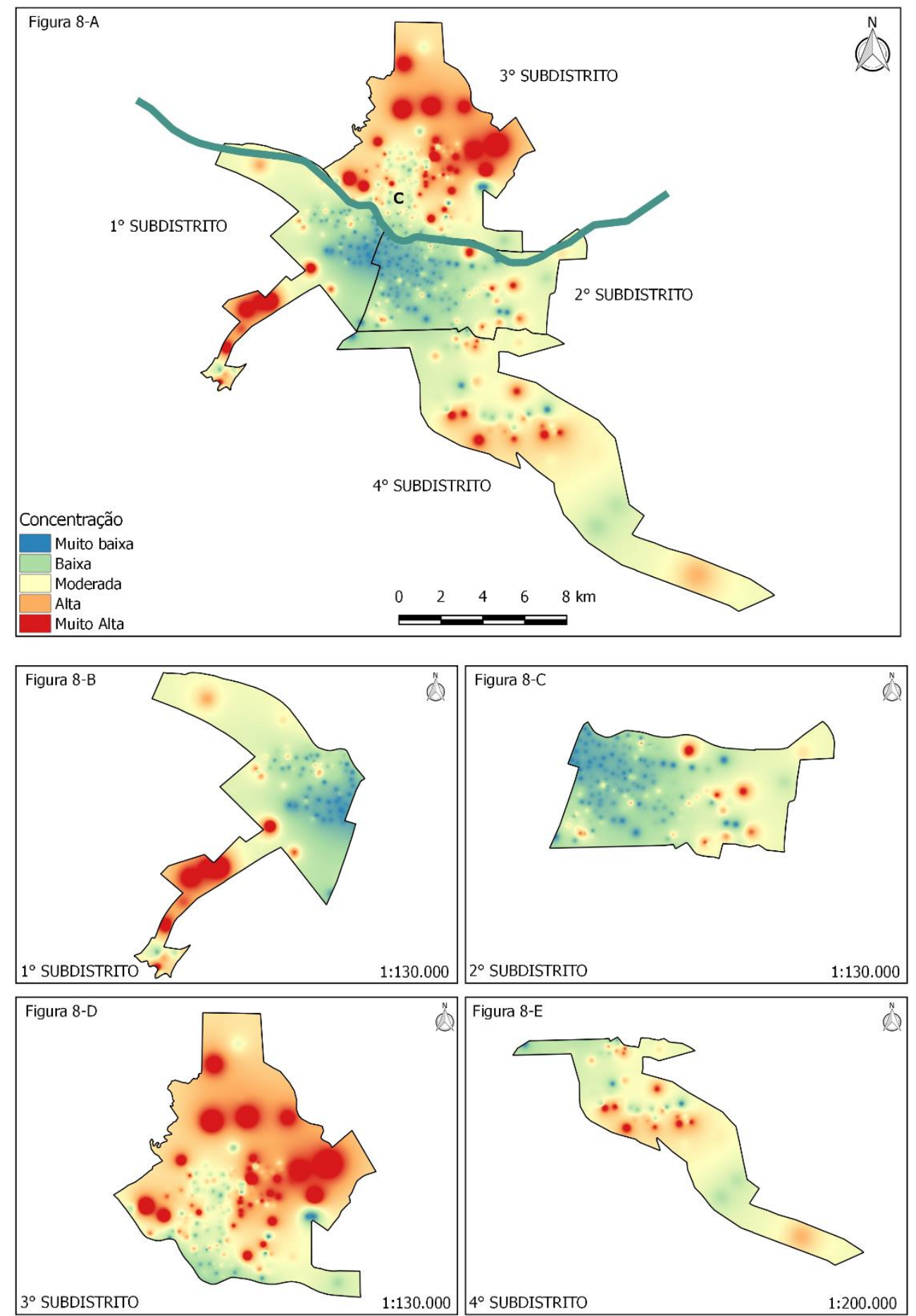

Fonte: Dados da pesquisa.

\section{Considerações finais}

Com o objetivo de analisar a segregação residencial na área urbana do $1^{\circ}$ distrito de Campos dos Goytacazes, o presente estudo utilizou as duas dimensões objetivas propostas por Sabatini e Sierralta (2006), quais sejam, dispersão e 
concentração; e exposição e isolamento, por meio dos índices de dissimilaridade e de isolamento. Como colaboração metodológica neste processo de análise, foi incorporado o mapa de calor, funcionalidade do software QGIS. Para a extração dos dados municipais, utilizou-se o Censo Demográfico de 2010 como base e, mesmo que a defasagem temporal possa não revelar exatamente a realidade atual, crê-se que a maior contribuição do artigo deriva da proposta metodológica, pois, além de poder ser replicada com dados atualizados, apresenta uma possibilidade de uso de ferramenta de estatística espacial associada aos índices não espaciais na análise da segregação residencial.

Existe uma expressiva produção sobre segregação residencial, e tem crescido o interesse por esses estudos nas últimas décadas. De acordo com os índices referenciados, principalmente pela metodologia encontrada em Sabatini e Sierralta no objeto desse trabalho, decidiu-se pela inserção da dimensão quantitativa a partir dos dois índices, daí a escolha da variável domicílio por faixa de renda como expressão da renda dos grupos sociais, o que conduz as lentes para aspectos socioeconômicos bastante sensíveis e reveladores da realidade. É inconteste que a contribuição dos índices de dissimilaridade e de isolamento tem sido valorizada, o que não dispensaria uma investigação qualitativa. Acredita-se que este somatório do qualitativo com o quantitativo representa um complemento que achega à integralidade no espectar, minuciar e avaliar a dinâmica socioespacial.

À medida que a compreensão dos meandros da segregação urbana se amplia nos estudos sobre esse fenômeno social, percebe-se o quanto a mineração desses dados poderá ultrapassar o restrito tratamento acadêmico e alcançar o campo de práxis social, podendo subsidiar discussões para a efetivação de políticas públicas na área habitacional. Tratando-se destas políticas em particular, cumpre ressaltar, sem desvalorizar o papel de programas sociais já adotados, que ainda não se tem dedicado preocupação em reverter a segregação e possibilitar uma urbanidade maior aos trabalhadores de baixa renda. Sob decisão oficial e sob o campo de uma política habitacional, adjetivada como social, contraditoriamente, amplia-se esse quadro em lugar de um maior equilíbrio na implantação das residências. É pertinente relembrar que questões referentes à posse da terra urbana constituemse em um campo de conflito e de interesses distintos entre a sociedade, o poder público e a lógica do capital, e o resultado visível desse embate tem sido a submissão do Estado à racionalidade do lucro e consequente segregação espacial e simbólica da população mais pobre da cidade. Segundo Cruz e Terra (2015), o capital promoveu "forte concentração da terra urbana, com o agravamento do processo de periferização precária, com consequente favelização, aumentando a segregação espacial, elevando o preço da terra e da moradia", realidade que, no Brasil, não se distancia do cenário da América Latina. Em especial nesses últimos anos, a moradia a que as classes de baixa renda têm tido acesso como um bem em decorrência dos programas habitacionais tem trazido como condicional corolário localização compulsória com cruciais dificuldades para suas vidas, sendo bastante comum a inobservância de itens cruciais, como o acesso a transporte e a equipamentos públicos na esfera da educação, da saúde, do lazer, entre outras; enfim, um conjunto de condições essenciais para o exercício do direito à cidade. Em visível precariedade, a convivência nessas comunidades de baixa renda termina por favorecer a conquista e o controle desses espaços por milícias, cuja forma de 
atuação favorece o aumento da violência e da marginalidade, subsumindo o papel do Estado e comprometendo a função social, traço comum no cenário nacional, assim como em Campos dos Goytacazes.

\section{REFERÊNCIAS}

AMARAL, E. F.L; LIMA AMARAL, C.V de. Estruturas invisíveis de segregação na Região Metropolitana de Goiânia. Revista Brasileira de Estudos de População, v. 36, 2019.

ARRETCHE, M. (Org.). Trajetórias das desigualdades: como o Brasil mudou nos últimos cinquenta anos. 1.ed. São Paulo: Editora Unesp, 2015.

BARROS, A. P. B. G; MEDEIROS, V. A. S. de; MORAIS, M. P. URBAN ACCESSIBILITY AND SPATIAL SEGREGATION IN BRAZILIAN CITIES: A CONFIGURATIONAL PERSPECTIVE1. 2017. Discussion paper / Institute for Applied Economic Research Brasília : Rio de Janeiro : Ipea. Disponível em: https://www.ipea.gov.br/portal/images/stories/PDFs/TDs/ingles/td_227.pdf. Acesso em: 28 out. 2020.

CASTELLS, M. A questão urbana. Rio de Janeiro: Paz e Terra, 1983.

CORRÊA, R. L. Trajetórias geográficas. 3 ed. Rio de Janeiro: Bertrand Brasil, 2005.

CRUZ, J. L.; TERRA, D.C.T. Indústria Extrativa Petrolífera Fluminense e Limites ao Desenvolvimento Regional - Repercussões no Território. Santa Cruz do Sul, RS. 2015.

DEUS, B. V.; ZEILHOFER, P.; ARAUJO, G. C.; SANTOS, A. S. L. Interpolação pluviométrica na Bacia do Alto e Médio Rio Teles Pires: uma análise de séries históricas e interpoladores. In: SIMPÓSIO BRASILEIRO DE CIÊNCIAS GEODÉSICAS E TECNOLOGIAS DA GEOINFORMAÇÃO, 3, 2010, Recife. Anais... Recife: UFPE, 2010. p.1-7.

DUNCAN, O. D.; DUNCAN, B. A methodological analysis of segregation indexes. American Sociological Review, n. 20, p. 210-217, 1955.

FREITAS, K. P. da S. Produção e apropriação do espaço urbano de Campos dos Goytacazes - RJ: da residência unifamiliar aos edifícios de apartamentos. 2011. Dissertação (Mestrado em Políticas Sociais) - Universidade Estadual do Norte Fluminense Darcy Ribeiro. 2011.

INSTITUTO BRASILEIRO DE GEOGRAFIA E ESTATÍSTICA (IBGE). Censo Demográfico do Brasil. Rio de Janeiro: IBGE, 2010. 
JAKOB, A. A. E.; YOUNG, A. F. O uso de métodos de interpolação espacial de dados nas análises sociodemográficas. In: XV Encontro Nacional de Estudos Populacionais, Abep, Caxambu - MG, Anais... 2006, p. 1-22.

KOWARICK, L. A espoliação urbana. Rio de Janeiro: Paz e Terra, 1979.

LIEBERSON, S. An Asymmetrical Approach to Segregation. In: PEACH, C.; ROBINSON, V.; SMITH, S. Ed. Ethnic segregation in cities. London: Croom Helm Ltd., 1981. p. 61-82.

MARICATO, $\mathrm{H}$. et al. Cidades Rebeldes. Passe livre e as manifestações que tomaram as ruas do Brasil. São Paulo. Boi Tempo: Carta Maior, 2013.

MARTINES, M R et al. Spatial segregation in floodplain: An approach to correlate physical and human dimensions for urban planning. Cities, v. 97, p. 1-10, 2020.

MITAS, L; MITASOVA, H. Spatial Interpolation. In: COBURN, Timothy C. Geographical Information Systems: Principles, Techniques, Applications and Management. 2. ed. New York: Wiley, 1999. p. 1-11240.

MUMFORD, L. A cidade na história: suas origens, transformações e perspectivas. São Paulo: Martins Fontes, 1998. $4^{\text {a }}$ ed.

PALMA, J. A. S. da. Segregação residencial em Salvador. Dissertação de Mestrado (do Programa de pesquisa em Pós-Graduação da Faculdade de Arquitetura e Urbanismo). Universidade Federal da Bahia. 2009.

PIQUET, R. Indústria e território no Brasil contemporâneo. Rio de Janeiro: Garamond, 2007.

RIBEIRO, L. C. de Q. Segregação residencial e políticas públicas: análise do espaço social da cidade na gestão do território. Revista Cidades, Comunidades e Territórios, Lisboa, n. 06, p. 33-50, jun.2003.

RIBEIRO, L. C. Q; LAGO, L. C. Reestruturação nas grandes cidades brasileiras: o modelo centro/periferia em questão. 1991. Disponível em: $<$ www.ippur.ufrj.br/observatorio/download/reestruturacao_cidades.pdf $>$. Acesso em: 19 jul.2017, 22:00.

SABATINI, F.; SIERRALTA, C. Medição da segregação residencial: meandros teóricos e metodológicos e especificidade latino-americana. In: Novas metrópoles paulistas: população, vulnerabilidade e segregação. CUNHA, J. M. P. da (Org.). Textos NEPO. Projeto Vulnerabilidade. 2006. pp.169-195.

SILVA, J.G.S.; PEREIRA, R.B; GUADAGNIN, M. R. SEGREGAÇÃO ESPACIAL E SEGREGAÇÃO SOCIAL: UM BREVE OLHAR SOBRE A CIDADE DE CRICIÚMA. Tecnologia e Ambiente, v. 24, p. 14-31, 2018. 
TORRES, H. G.; MARQUES, E.; FERREIRA, M. P.; BITAR, S. Pobreza e espaço: padrões de segregação em São Paulo. Estudos Avançados, v. 17, n. 47, p. 13-42, jan.2003.

Ítalo Matias. Doutorado na COPPE em Engenharia Civil pela Universidade Federal do Rio de Janeiro (2007) na área de Sistemas Computacionais. Professor titular da Universidade Candido Mendes (Campos dos Goytacazes). E-mail italo@ucamcampos.br

Carla Nogueira Patrão de Aquino. Doutoranda do Programa de Pós-Graduação em Planejamento Regional e Gestão da Cidade/Universidade Candido Mendes. Assistente Social no Instituto Federal de Educação Ciência e Tecnologia Fluminense. E-mail cnpatrao@gmail.com

Luiz Pereira. Mestrado em Planejamento e Gestão de Cidades pela Universidade Cândido Mendes. Professor do Instituto Federal Fluminense. E-mail luizcaldas.iff@gmail.com

Fabio Freitas da Silva. Doutorando em Planejamento Regional e Gestão da Cidade/Universidade Candido Mendes.E-mail fabio1_freitas@hotmail.com

Como citar: MATIAS, Ítalo et al. Uma proposta metodológica para estudo de segregação residencial como fenômeno relacional. Redes (St. Cruz Sul, Online), Santa Cruz do Sul, v. 25, p. 2320-2342, 2020. ISSN 1982-6745. doi:https://doi.org/10.17058/redes.v25io.14534.

\section{CONTRIBUIÇÃO DOS AUTORES}

a. fundamentação teórico-conceitual e problematização: Ítalo Matias, Carla Nogueira Patrão de Aquino, Luiz Pereira, Fabio Freitas da Silva

b. pesquisa de dados e análise estatística: Fabio Freitas da Silva, Carla Nogueira Patrão de Aquino

c. elaboração de figuras e tabelas: Fabio Freitas da Silva, Carla Nogueira Patrão de Aquino

d. fotos: não se aplica

e. elaboração e redação do texto: Ítalo Matias, Carla Nogueira Patrão de Aquino, Luiz

Pereira, Fabio Freitas da Silva

f. seleção das referências bibliográficas: Ítalo Matias, Carla Nogueira Patrão de Aquino, Luiz

Pereira, Fabio Freitas da Silva

Fontes de financiamento: não se aplica. 